\title{
Risks of systemic transformation in energy companies
}

\author{
L. D. Gitelman \& M. V. Kozhevnikov \\ Department of Energy and Industrial Management Systems, \\ Ural Federal University, Russia
}

\begin{abstract}
Among the various risks (financial, technological, environmental, market) that accompany the energy production systemic (strategic) risks are the most complex and difficult in terms of valuation, allocation of control object and determining the consequences. The key feature to manage those risks is the almost complete absence of statistical data on the impact and consequences of organizational innovations. It should be understood that each organizational decision, especially in the energy companies, is largely unique and can lead to transformation of the whole management system in power companies and even in the energy market. The paper contains a model of strategic risk management, based on the priority results setting. Original organizational risk assessment methodology was formed as well as mechanisms of suppression of their sources were established. Testing of methods is carried out for the key energy production result that is "reliability of electricity supply".

Keywords: risks, power companies, organizational innovations, risk-related area, reliability of energy supply.
\end{abstract}

\section{Introduction}

Depending on the approach to managing risks, all structural changes in power companies may be divided into three groups.

The first one contains "risk-free" decisions. They usually are local changes, connected with, e.g. automation of certain managerial processes, minor streamlining of managerial structures etc. Job cuts caused by such measures and a decrease in corresponding expenses can be easily defined by the "count-up" method [1]. 
Solutions falling into the second group are aimed at certain economic and social results. However, their initial assessment demands a probabilistic approach. These changes are normally of "behavioral type", they are concerned with those elements of the management system where their effect depends directly on the adequate reaction of employees, which is more or less unpredictable. It might be an upgrade to the mechanism of motivation which is carried out with the aim of reducing personnel turnover and increasing performance. In this case, the risk of the structural decision is accounted for through the mean value of corresponding final results counted by the machinery of expert assessments.

The third group consists of radical structural changes of a systemic type, aiming to bring the management of the power company to a crucially new quality level. These are deep radical changes in ideology and technology of management affecting the fundamentals of corporate philosophy and involving reengineering all key business processes in the company. It should be realized that carrying out such complex changes contains factors which, under unfavourable circumstances, are able to cause serious deformations in the management system of the company, a sharp decline in its performance and even financial crisis [2]. To prevent and localize such threats (risk events), it is necessary to know the kinds of risks, their sources, type of possible threats and their symptoms (indicators). So managing risks in such reforms has considerable methodological peculiarities which are contemplated further in the article.

\section{Research methodology}

The peculiarity of managing structural risks lies in the almost complete absence of statistics for the performance and consequences of structural innovations in power companies. It should be considered, too, that every structural decision is largely unique at its core. So one has to use prior and indirect expert assessments based on analyses of data like the following:

- financial and economic conditions of the company at the beginning of changes;

- $\quad$ the level of personnel readiness to accept deep structural changes;

- $\quad$ the readiness of managers at different levels to conducting change;

- $\quad$ the level of detail in specific projects and programs of change;

- the degree of top management awareness of the authorities' intention to carry out local reforms in the electric power sector, changes in legislation etc.

To analyze structural risks and risk management in power companies, their classification has been developed. It is shown in the table 1. The following classification features were identified.

Level of risk. It is necessary to divide structural risks by this criterion for making decisions related to a particular direction of transformations and their radical character. If the risk is deemed to be negligible, it does not have to be taken into account. If the risk is unacceptable, the decision should probably be discarded. At intermediate values, relevant risk minimization measures should be taken. 
Table 1: Classification of risks of structural innovations in an electric grid company.

\begin{tabular}{|c|c|c|}
\hline $\begin{array}{l}\text { Classification } \\
\text { criterion }\end{array}$ & Type of risk & Comments \\
\hline \multirow{2}{*}{$\begin{array}{l}\text { Scope } \\
\text { (radicality) of } \\
\text { changes }\end{array}$} & Local & $\begin{array}{l}\text { Connected with changes in specific elements of } \\
\text { management system }\end{array}$ \\
\hline & Systemic & $\begin{array}{l}\text { Connected with cardinal reformation of the } \\
\text { whole management system }\end{array}$ \\
\hline \multirow{5}{*}{$\begin{array}{l}\text { Level of risk } \\
\text { (expert } \\
\text { estimates) }\end{array}$} & Negligible & Close to zero \\
\hline & Low & Less than $30 \%$ \\
\hline & Intermediate & From 30 to $60 \%$ \\
\hline & High & From 60 to $80 \%$ \\
\hline & Unacceptable & More than $80 \%$ \\
\hline \multirow{3}{*}{$\begin{array}{l}\text { Sources } \\
\text { (factors) of } \\
\text { risk }\end{array}$} & Personnel & Personnel unprepared for change \\
\hline & Operational & $\begin{array}{l}\text { The concept is not justified and there are } \\
\text { mistakes in carrying out innovations }\end{array}$ \\
\hline & Regulatory & $\begin{array}{l}\text { Unstable government policy in reforms and } \\
\text { regulation of natural monopolies. }\end{array}$ \\
\hline \multirow{3}{*}{$\begin{array}{l}\text { Final results of } \\
\text { the company } \\
\text { performance }\end{array}$} & Technological & $\begin{array}{l}\text { Decrease in reliability of energy supply, higher } \\
\text { deterioration of equipment }\end{array}$ \\
\hline & Economic & $\begin{array}{l}\text { Growth of production expenses and decrease in } \\
\text { labour performance }\end{array}$ \\
\hline & $\begin{array}{l}\text { Commercial } \\
\text { (financial) }\end{array}$ & $\begin{array}{l}\text { Cut in volumes of realization and profit, change } \\
\text { in the cost of the company }\end{array}$ \\
\hline \multirow{2}{*}{$\begin{array}{l}\text { Position of the } \\
\text { company }\end{array}$} & External & $\begin{array}{l}\text { Is conditioned by frequent and rough } \\
\text { disturbance in the environment }\end{array}$ \\
\hline & Internal & $\begin{array}{l}\text { Is conditioned by the degree of preparedness of } \\
\text { the company to reforms }\end{array}$ \\
\hline \multirow{2}{*}{ Controllability } & Controllable & Can be accounted for and minimized \\
\hline & Uncontrollable & Can be accounted for, but cannot be minimized \\
\hline \multirow[t]{2}{*}{$\begin{array}{l}\text { Field of } \\
\text { changes }\end{array}$} & Profile & $\begin{array}{l}\text { Connected with changes on the main sphere of } \\
\text { activity }\end{array}$ \\
\hline & Diver & Connected with creating additional businesses \\
\hline \multirow{2}{*}{$\begin{array}{l}\text { Results of } \\
\text { change }\end{array}$} & Main & $\begin{array}{l}\text { Likelihood of losses of the expected results of } \\
\text { changes }\end{array}$ \\
\hline & Related & $\begin{array}{l}\text { Likelihood of getting undesirable results of } \\
\text { changes }\end{array}$ \\
\hline \multirow{2}{*}{ Risk events } & Primary & Decrease in management performance \\
\hline & Secondary & Deterioration in final results of the company \\
\hline
\end{tabular}

Position of the company. "External" and "internal" risks are substantially different in the power of their sources as well as in the ability of the company to influence their level. In particular, the unstable macro and micro environment in which the company functions makes one pay special attention to "external" risks. 
Controllability. We regard "internal" risks as fully controllable and due to be minimised. As regards "external risks", the situation is not univocal. A certain part of them is seen as not managed by the company. But the other part can be influenced indirectly to some degree using a range of different methods. In any case, one has to constantly monitor the environment and track down controllable and uncontrollable components of "external" risks.

Sources of risks. This classification is important because it grasps the whole process of managing changes in a power company, from concept formulation and personnel training to tracking and analyzing the consequences of "systemic fluctuations" at the level of the state economic policy and in the sphere of regulating natural monopolies. The latter is especially important to the reform and integration of grid companies into the market.

Field of changes. This classification is also directly related to a grid company that seeks to diversify its business and enter ancillary services markets. Naturally, approaches to organizational risk management in the sphere of regulated business activity (distribution of electricity) and unregulated business will have significant differences.

Results of changes. Here the following point is important: associated risk can turn out to be much more important than the main risk, if its source is powerful. For instance, the lack of personnel training for changes, serious blunders in conceptual provisions for the reforms, operational mistakes during their implementation can cause dangerous destructive effects on the personnel of the power company, a sharp decline in the management's innovation activity and even make the company unmanageable.

Final results of the company performance. Eventually all structural changes must contribute to an increase in innovation activity, production efficiency and competitive ability of the company in a market system. The dynamics of corresponding final results show the success of the carried out reforms and act as a basis for adjustment of all reengineering decisions in the company.

Scope (radicality) of changes. This classification is needed to distinguish methodological approaches to the management of different kinds of risks. As was shown above, local risks are common to those groups of structural decisions which are aimed at getting specific predetermined results. Systemic risks are typical of radical changes in management and they need a specific "heuristic" approach which is suggested in this work.

Risk events. Here risks are divided according to consequent risk events of two types: connected with deformations in management system (level 1) and a decline in final results of the company performance (level 2). The primary risks are, therefore, personnel, operational and regulatory ones, and the secondary risks are technological, economical and commercial. The given classification is used for developing a model of the risk environment (see below).

The suggested classification makes it possible to define the structure of organizational risk and identify approaches to assessment and minimization of its specific types.

We also introduce the notion "risk environment", which means a specific environment where processes of structural innovation of the strategic type are 
carried out [1]. The figure 1 shows structural elements of the model of risk environment developed on the basis of the given classification of structural risks. Solid lines show the main connections, dotted lines - additional ones. According to this model, the risk environment includes (in downward direction):

- $\quad$ sources of primary risks;

- primary risks;

- $\quad$ risk events of the first level (caused by failures and deformations in the management system);

- $\quad$ secondary risks;

- $\quad$ risk events of the second level (connected with deterioration of the company performance).

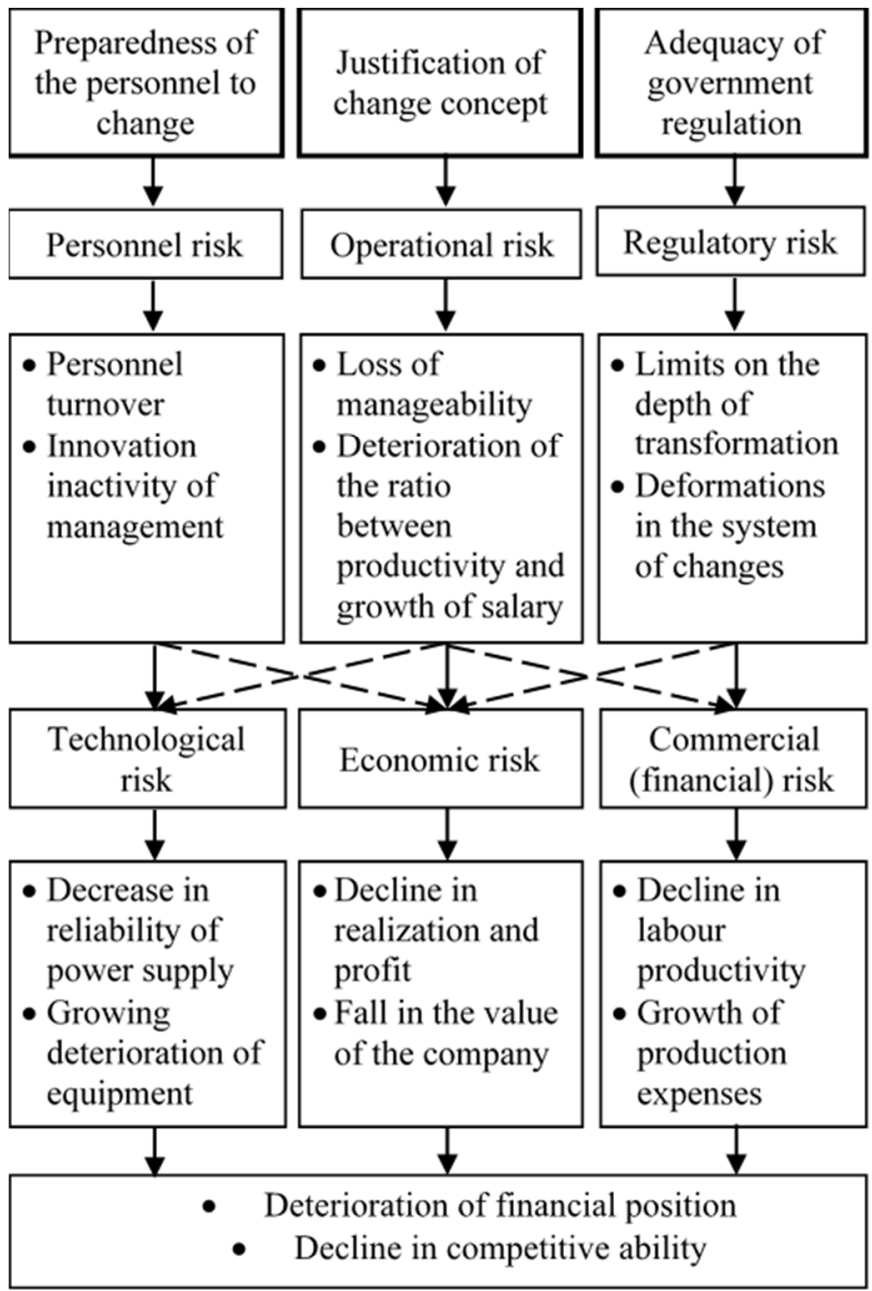

Sources of risks are not defined, assessed or suppressed<smiles>CC1CCC1</smiles>

Risk events of the first level are happening that are connected with decrease in performance of the power company

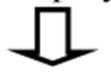

Measures aimed at adjusting management system factors are not taken. Risk events of the second level are growing that are connected with degradation of the company performance

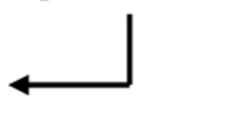

Figure 1: Model of structure of risk environment. 
As one can see from the model, the risk events of the first level in case of their occurrence turn into the sources of secondary risks and may with some degree of probability initiate a decrease in the final results of the company.

The right side of the figure depicts a negative scenario of actualization of risk events in case risk assessment is ignored and a lack of risk management.

On the basis of the model of risk environment a method of structural risk assessment is created and a relevant mechanism for suppressing it is formed.

The risk of structural decision (innovation) of a radical type (in our classification it is a systemic risk) should be understood as a probabilistic threat of deterioration of the results of the company. Using the classification of risks and the model of risk environment, the following method of defining a systemic risk can be offered (1):

$$
R_{j}=N_{i} \cdot P_{i} \cdot P_{j i}
$$

where $\mathrm{R}_{\mathrm{i}}$ - risk of deterioration of the final result $j$ of the power company (or occurrence of $j$ type event); $\mathrm{N}_{\mathrm{i}}$ - power of the risk source of $i$ type event, preceding $j$ type event and acting as its factor ( $j$-type event is related to a decrease in efficiency of management system in the power company); $\mathrm{P}_{\mathrm{i}}-$ probability of decrease of event $i ; \mathrm{P}_{\mathrm{ji}}$ - probability of fulfillment of the event $j$ under the influence of actualized event $i$.

\section{Testing the methodology}

We will demonstrate the application of the suggested method on one simplest example. Let us choose the reliability of electricity supply as the final result of the power company performance. Thus, risk event $j$ actualizes - "decrease in reliability of electricity supply". It is seen from the scheme in the figure that this event is connected with technological risk. Event $i$ is increasing personnel turnover, that is, this event triggers event $j$. Moreover, turnover is seen as a result of blunders in the management system. Turnover is mediated by personnel risk, the source of personnel risk is insufficient preparedness of staff for changes.

The power of the source of risk can be estimated expertly on a 100-point scale, shown in percentage points. Given the method of defining personnel preparedness and the corresponding scale for our example, the power of the source of personnel risk will be

$$
N_{i}=100-L
$$

where $\mathrm{N}_{\mathrm{i}}$ is the power of risk source, $\mathrm{L}-$ level of personnel preparedness, $\%$.

It is worth noting that in formula (1) the product of power of risk source multiplied by the probability of the $i$-event (i.e. personnel turnover) gives us the estimate of the personnel risk, and the whole formula shows technological risk (related to the decrease in reliability).

Probabilities $\mathrm{P}_{\mathrm{i}}$ and $\mathrm{P}_{\mathrm{ji}}$ are the most difficult ones to estimate. In this respect, experts can get help from some "rough" targets, following out of the logic of processes happening in the risk environment of structural innovations. In particular, it is possible to follow the three simple rules below.

1. Both factors $\left(\mathrm{P}_{\mathrm{i}}\right.$ and $\left.\mathrm{P}_{\mathrm{ji}}\right)$ increase as the power of risk source grows. 
2. If $\mathrm{L}<50 \%$, than $\mathrm{P}_{\mathrm{i}}>0.5$ (if the level of preparedness is less than $50 \%$, the probability of staff turnover is more than 0.5$)$.

3. $\mathrm{P}_{\mathrm{ji}}>\mathrm{P}_{\mathrm{i}}$ (probability of a decrease in reliability of electricity supply due to personnel turnover is higher than probability of an increase in personnel turnover due to personnel unpreparedness for change).

Let us suggest that for our example we got the following estimates: $\mathrm{L}=30 \%$, $\mathrm{P}_{\mathrm{i}}=0.7, \mathrm{P}_{\mathrm{ji}}=0.8$. Then the technological (secondary) risk of a decrease in supply reliability during the fulfillment of this structural innovation according to (1) and (2) will be: $\mathrm{P}_{\mathrm{j}}=(100-30) * 0.7 * 0.8=39.2 / 40 \%$.

At that personnel (primary) risk is $49 \%=[(100-30) * 0.7]$.

According to the given classification (see table 1) a $40 \%$ risk is intermediate and cannot be ignored. Consequently, it is necessary to take measures to neutralize (suppress) the corresponding source of risk.

Similarly, the assessment of the remaining kinds of secondary risks is carried out: economic and commercial (financial). We would like to highlight that risks must first be analyzed individually for different final results. As it is shown in the figure 1 , every risk has its own corresponding results. Then mean average values for the three risk estimates are calculated considering the index of relative importance of these results for the power company. It is only after that decisions on dealing with the sources of corresponding primary risks are made.

For example, the following values of primary risks have been received: technological $-40 \%$, economic $-25 \%$, commercial $-5 \%$. This implies that main efforts should be concentrated on suppressing the source of personnel risk. The source of operational risk does not have to be handled directly, but it is necessary to control the state of the company's management system during the transformation to detect and localize the risk events of the first level on time (see figure.). As for regulatory risk (supreme as compared to commercial), it can be ignored altogether.

\section{Economic risk reduction in the course of interaction between energy companies and consumer}

Industrial development makes interaction between power companies and consumers closer and more intense. Consequently, companies face greater risks. The energy company finds it most difficult to manage systemic risks, whereas for industrial consumers the biggest challenge is economic (market risks).

The risks faced by consumers in a competitive electricity market are the following:

- $\quad$ price fluctuations in a spot market. These are mainly caused by changes in the supply and demand for electricity, with falling prices being undesirable for sellers and rising - for buyers;

- non-execution of a contract (in terms of prices and amount of electricity to be delivered) in a contract market;

- $\quad$ rejection by the market operator of a price bid in the process of competitive capacity outtake; 
- a lack of match between the consumed amount electricity and planned consumption.

Unfavourable electricity price fluctuations are particularly disruptive because they hurt the financial performance of the company and make energy cost reduction planning less reliable.

The following market risk reduction methods could be recommended to consumers operating in a competitive market.

Technological solutions. The key trend is to ensure the flexibility of power supply by making use of one's own power generating units and (or) shutting down a part of equipment during high-price periods (peak hours).

Organizational solutions. These suggest establishing industrial and regional alliances of manufacturing companies that would facilitate their effective operation in the competitive energy market. Such associations could set up their own energy trading companies or sign contracts with existing ones for, among other things, managing expertly all types of market risks. It is advisable to set up energy trading departments within individual companies during a reorganization of energy management to operate effectively in the new environment.

Direct contracting. A bilateral contract is an agreement between a buyer and a seller to supply electricity at prices that are fixed for a specified period of time. However, bilateral contracts, especially those stipulating physical delivery of electricity, are sometimes fraught with problems such as the risk of non-execution of contractual obligations, the difficulty of establishing a mutually acceptable price and of finding effective suppliers. The latter tend to sign direct contracts only with the most lucrative clients - major energy consuming companies. This circumstance makes financial contracts (in combination with buying electricity on a spot market) more preferable in many cases.

Financial (commodity market) instruments for risk management. Standardised futures and options contracts for electricity that are traded in commodity markets as well as their numerous combinations are considered to be one of the most efficient price risk management tools. The risk of contract breach is mitigated, too, because the commodity market with its highly effective financial assurance mechanism acts as an intermediary between the buyer and the seller of futures.

Supplier diversification. It is advisable, when possible, to buy required amounts of electricity (capacity) in portions from various sectors of the market (spot, contract and regulated markets) and from various suppliers (including generators and retailers). The combined risk is, therefore, distributed across a large number of contracts (suppliers).

\section{Conclusion}

1. The ultimate risk control concept for strategic structural changes is based on a number of provisions:

- $\quad$ risk management has to be organized as a continuous process including three stages: preparation, implementation of changes, final stage; 
- the results of preliminary risk assessment provide grounds for deciding on the reasonability, forms and methods of handling specific kinds of risks;

- $\quad$ in the course of transformations, monitoring of the main factors of the company management system is carried out in order to detect symptoms of risk events of the first level (personnel turnover, loss of controllability, blunders in the system of incentives, regulatory deformations etc.) and to make necessary adjustments. This is caused by the instability of risk sources and their ability to come to life with the time after being suppressed;

- $\quad$ at the end of the first stage, complex control of all results is carried out and a decision is made whether to move on to the second stage.

2. Training for personnel, especially managers at all levels, to prepare them the upcoming change should be considered the most universal and effective way of minimizing structural risks. It is also necessary to substantiate the concept of changes and its implementation programme very carefully.

We recommend starting transformations with less risky steps, acting on the principle of the lying cone or pyramid. It makes it possible to warm up the team of innovation managers well, gradually complicating tasks and accumulating decision-making experience. In the course of implementation of the programme it is necessary to watch out for interim results of the innovation in order to make adjustments to the innovation process in advance, without allowing serious blunders or failures to happen.

3. At the same time, monitoring of the environment should be carried out with an emphasis on the behavior of consumers, competitors and especially authorities. In this regard, the best way to minimize risks is to maintain constant and reliable contact with these subjects. It is helpful to organize regular collection of information on the results of changes with similar ultimate goals that were implemented in other power companies. If the information on failures becomes available, then changes should be put on hold with a comprehensive analysis of the colleagues' failures. It should be remembered that abandoning a decision that is "too risky" or postponing it is another reliable way to minimize risk.

\section{References}

[1] Gitelman, L.D., Volkova, I.O., Kozhevnikov, M.V. \& Rostik, O.M., Organization of the innovation process in the power company, (in Russian), Economy: Moscow, 2014.

[2] Gitelman, L.D., Russian power sector reform: lessons for developing countries. Proc. Of the 1st Int. Conf. On Energy Production and Management in the 21st Century: The Quest for Sustainable Energy, eds. C.A. Brebbia, E.R. Magaril \& M.Y. Khodorovsky, WIT Press: Southampton, pp. 19-26, 2014. 